by taking advantage of an $(n, \gamma)$-process due to the reaction of slow neutrons with indium, and subsequent conversion of the indium isotope with the emission of $\beta$-radiation. The $\gamma$-and $\beta$-rays produce electron-hole pairs, so that at an InP $p-n$ junction an e.m.f. is developed the decay of which after irradiation enables one to infer the neutron flux.

Papers on specific groups of materials included a discussion of the mechanism of luminescence in silver halides (Z. Matyaš, Prague). New ternary compounds with semiconductor properties were discussed briefly in two papers, and D. A. Wright (General Electric Co., Wembley) reported on the properties of bismuth telluride, which is suitable for studying the problems of thermoelectric refrigeration. Organic systems were also discussed. H. P. Kallmann (New York) put forward considerations which suggest that the energy transfer in liquid organic systems is by collision rather than by irradiation. He also reported experiments on photoconductive effects in organic crystals in which the motion of holes appears to dominate.

Papers submitted to the colloquium, but not read, included one on the electrical properties of some binary compounds by $D$. N. Nasledov (Leningrad) and another on the breakdown of $p-n$ barriers by B. M. Wul (Lebedew Institute, Moscow), and participants of the colloquium were glad to be able to discuss with the authors recent Russian work in these and related fields.

It is a tribute to the work of the organizers that the texts of most of the invited papers and the abstracts of most shert papers were in the hands of the participants before the meeting. Nevertheless, there was comparatively little discussion in the open meetings ; though, if time had been allocated explicitly to discussion, there would have been numerous contributions from the floor, judging from the many fruitful private conversations which were proceeding betwern meetings.

It is regretted that several interesting papers cannot be mentioned here, but enough has probably been said to indicate that a very wide field was covered. While it is true that no new band structure calculations were reported, and impurity band conduction was touched on only incidentally, it is in fact difficult to think of any other basic topic which was not raised in one or other of the papers submitted. The proceedings will be published early in 1957 as volume 4 of "Halbleiterprobleme" (Friedr. Vieweg u. Sohn), with each contribution in its original language.

P. T. LANDSBERG

\section{EXTRUSION AND ROLLING PROCESSES}

\footnotetext{
THE September conference of the British Society of Rheology held in Sheffield during September 27-28 had as its title "Kxtrusion and Rolling Processes". The varied interests of members of the Society were fully illustrated by the wide scope of the papers presented. Each had in common some particular aspect of rheological behaviour. The conference, consisting of the presentation of six papers and the attendant discussions, was opened by the president, Prof. J. G. Oldroyd (University College of Swansea).
}

"Some Applications of Kheology in the Investigation and Practice of Polymer Extrusion" was the title of a paper by W. F. O. Pollett (Henley's Research Laboratories). The simple screw extruder is exten. sively used in the electric cable industry for the application of dielectric and protective coverings, coinposed essentiallv of high polymers. Standard quantitative treatments of the theory of screw operation in conjunction with viscous materials have been based, erroneously, on the assumption that the thermoplastics and rubbers used in the cable industry exhibit Newtonian behaviour. The Ostwald de Waele relationship provides a somewhat closer approximation to practice within certain limits of screw design.

The use of different coloured materials is a standard method for mapping flow-puths in an extruder and can be supplemented by two complementary tech. niques. Strains can be 'frozen in' many high polymers by a reduction in temperature, and elastic recovery will afterwards occur if the temperature is again raised. The recoverable strains produced in plasti. cized polyvinyl chloride during its passage through the extruder can be stabilized in this way and their dis. tribution studied by the reheating of suitable samples. Further, the temperature at which recovery occurs depends upon that at which the polyvinyl chloride was deformed. These methods have greatly assisted the correct design of $\mathrm{T}$-heads used for the application of extruded wire and cable coverings. It has been shown that when material emerges from the screw channel, it converges towards the axis of the barrel in consequence of the Weissenberg effect. Unless the boundaries are suitably shaped, this will result in stagnant zones leading to decomposition of the polymer or to premature curing in the case of vulcanizable compositions.

When the conditions at the die are such as to favour the formation of high recoverable strains, there is a tendency for the exudate to exhibit a characteristic type of surface roughness probably caused by the stretching of the surface layers as the velocity gradient existing in the die is dissipated in the vicinity of the die mouth. This effect can often be avoided by an increase in temperature; or, if this is impracticable, by maintaining by special die design a shear-rate of $10^{4}-10^{5}$ sec. $^{-1}$ for a sufficiently long time.

The determination of extrusion variables and the principal features of press design can be treated theoretically as shown by P. Feltham (University of Leeds) in his paper "A Simple Theory of the Criteria of Press Design and Process Efficiency in the Industrial Extrusion of Metals". In the direct extrusion process, work done by the ram is expended on useful plastic work in reducing the dimensions of the metal from $A_{0}$ to $A$, where $A_{0}$ is the cross-sectional area of the billet and $A$ that of the extruded bar. Work is wasted due to friction at the billet/container interface, as well as on plastic work which does not yield a final plastic deformation. Since flow during extrusion is essentially streamlined, useless work of this latter kind is very small and is neglected in the theory. The maximum extrusion pressure can be shown to be: $\sigma_{\max .}=Y_{a} \mid \ln \left(A_{0} / A\right)^{7} \exp \left(4 \mu L^{\prime} / D\right)$, where $Y_{a}$ is the tensile yield stress of the fully workhardened material at the extrusion temperature, $l l$ is the effective coefficient of friction at the billet/ container interface, $L^{\prime}$ is a length slightly smaller than the billet length and $D$ is billet diameter. The strain-rate in the 'virtual die' formed by 'dead metal' near the true die orifice is approximately equal to 
$(3 V \mid D) \ln \left(A_{0} \mid A\right)$, where $V$ is ram velocity. $Y_{a}$ depends on strain-rate and temperature and can be obtained from high-temperature rheological data for metals at high strain-rates. Extrusion forces calculated from the theory for aluminium, copper and lead using a wide range of extrusion temperatures, extrusion ratios, ram velocities and billet dimensions showed very good agreement with experimental results. 'The maximum extrusion force $F_{\max }=A_{0} \sigma_{\max }$. has a minimum for a given value of $A_{0}$ and fixed value of billet volume $V$. From the condition $\mathrm{d} F$ max. $/ \mathrm{d} D=0$, an optimum value of billet diameter $D$ can be determined. Such a determination could be particularly valuable when using a press near its maximum capacity. At very high temperatures with high extrusion ratios, the back shear stress at the billet surface due to friction may exceed the tensile shear stress of the metal. When this happens, a thin skin of metal adheres to the contained wall after extrusion, and the maximum extrusion stress then becomes $Y_{a}\left[\ln \left(A_{0} / A\right)+\right.$ $\left.\left(2 m L^{\prime} \mid D\right)\right]$, where $m=Y_{b} / Y_{a}$ and $Y_{b}$ is the tensile shear stress of the billet in the surface region.

In "The Use of Optical Methods in the Manufacture of Plastic Sheet", H. H. Allen (British Celanese, Ltd.) pointed out that optical methods can be usefully employed to obtain information about rheological conditions of both product and process in the continuous production of both cast and extruded plastic film or sheet. The instruments used should be simple and robust, and preferably utilize some projection technique. One instrument recently developed, using a technique based essentially on the schlieren method, can detect normal and abnormal flow lines, 'cold-flow' patterns and any impurities and inhomo. geneities.

Anisotropy often exists in thin plastic sheets and is generally caused by stresses due to flow in the extruder die or casting box. Orientation of sheet is of importance because of its general deleterious effect on physical properties. An interesting correlation exists between optical anisotropy and such physical properties as breaking strength and heat shrinkage, and its measurement can be used, therefore, to determine these important properties. Further, since its presence reflects to some extent the rheological behaviour of the process, it can be used to detect changes in operating conditions with consequent greater uniformity of product. Continuous measurement of optical anisotropy can be carried out by comparing on a screen the light transmission of the sheet and each of two pairs of crossed. 'Polaroids'. This instrument also determines the direction of orientation. Diverg. ence between extrusion or casting direction and direction of optical anisotropy indicates flow disturbance.

'The theoretical aspects of milling and calendering were discussed by E. B. Atkinson (P.X. Plastics, Ltd.) in his paper "Milling and Calendering of Plastics". In the mills and calenders used extensively in rubber and plastics technology, a 'bank' of plastic material is built up at the entrance side of the roll 'nip' and is squeezed through the roll gap as a continuous sheet. The flow regime in the plastic in the region between the rolls and the magnitude of the stresses arising are of considerable interest to the plastics technologist and the design engineer. The theoretical treatments of Ardichvili, Eley and Gaskell were based on assumptions of doubtful validity. Fxcept in the case of a high degree of slip (that is, with heavily lubricated compositions) the flow regime can be regarded as equivalent to the extrusion of plastic material through a slot of varying height, and the pressure distribution, roll thrust, and shaft torque determined by the shear stresses set up at the roll surfaces. Gaskell's treatment is based on these assumptions, but in its original form is not readily applied to non-Newtonian materials. Atkinson and Nancarrow have carried out a similar treatment based on an empirical power-law relationship between shear stress and velocity gradient. In this the pressure distribution, total roll thrust and shaft torque may be obtained from expressions which contain the rheological parameters, roll dimensions and speeds, and from.tables of numerically evaluated functions which depend upon the size of the 'bank' of plastic in the 'nip' and the exponent of the power law.

'Theoretical treatments of the rolling and extrusion processes are affected by a rise of temperature during the process. A paper on "Temperatures developed during Extrusion", by M. 'T. Watkins (Mechanical Engineering Research Laboratory, Department of Scientific and Industrial Research), was therefore of great interest. Suitable sub-presses were developed for the direct and inverted extrusion of rod and Hooker tubes and the inverted extrusion of tubular containers. The sub-press was set up for the appropriate extrusion and mounted in a 150-ton up-stroking hydraulic press. The extrusion load and punch stroke were measured by variable capacity gauges of the parallel-plate and concentric-cylinder types respectively. Temperatures within the slug were measured at four positions simultaneously by thermo. couples protected by high-tensile steel sheaths, it having been established that these sheaths had little if any influence on the flow pattern. Rods, Hooker tubes and tubular containers of chemical lead Grade $A$, aluminium 99.5 per cent, copper E.R.H.C. and $70 / 30$ brass were extruded at room temperatures at punch speeds of 1 to $30 \mathrm{in} . / \mathrm{min}$. All slugs excepting those used for studies on the effect of slug dimensions were of 1 in. and 2 in. diameter and of heights 1 in. and 2 in. respectively. The major factors contributing to the temperature rise inside the slug during extrusion were the reduction in area and punch speed. The highest recorded temperatures for the extrusion of lead and aluminium rod at 99.4 per cent reduction were $180^{\circ} \mathrm{C}$. and $280^{\circ} \mathrm{C}$. respectively, the thermocouples being located $\frac{1}{8}$ in. inside the slug. In the extrusion of lead at this reduction, an increase in punch speed from 1 in. to $5 \cdot 5 \mathrm{in.} /$ min. resulted in an increase in observed temperature from $90^{\circ}$ to $170^{\circ} \mathrm{C}$. With aluminium at 94 per cent reduction under similar conditions, the temperature increased from $65^{\circ}$ to $160^{\circ} \mathrm{C}$.

The difficulties inherent in the theoretical treatment of hot rolling were emphasized by $\mathbf{A}$. W. McCrum (British Iron and Steel Research Association) in a paper entitled "Theoretical Aspects of Hot Rolling". Despite its great importance technologically, the hot rolling process has received little theoretical treatment. Within the temperature-range of hot working, the frictional stress between the rolls and the stock approaches the yield strength of the material in shear, and as a consequence of this and the geometry of the process, the deformation is complex and in general is three-dimensional with the occurrence of appreciable increase in width (spread). A rigid theoretical solution of even the simplest problem, a rectangular bar between parallel rolls, is at present unobtainable without making many simplifying assumptions. Most of the early theories have been largely empirical, and only the analyses of Ekelund, Orowan and Sims can 
be said to have a theoretical basis. None of these treatments yields formulæ which can be widely used in practice. Of the many formulie proposed for the calculation of the spread of a rectangular bar between parallel rolls, that of Fkelund is of reasonable accuracy but too complex for practical utilization. A recent formula derived by Hill combines accuracy with simplicity; but a parameter representing the effect of either friction or the deformation behaviour of the material must be determined in advance. The practical requirements of a satisfactory theory of hot rolling are: (a) prediction of roll force and torque to the required degree of accuracy, and $(b ;)$ spread must be predicted so that the final product is within the required tolerance limits. Furthermore, this should be possible for all simple shapes such as diamonds, squares, ovals, etc. The problem is further complicated by the modern use of continuous multistand rolling, where a knowledge of stock entrance and exit speeds for a given velocity of roll surface is essential.

D. HARDWICK

\section{THE BRITISH ELECTRICAL AND ALLIED INDUSTRIES RESEARCH ASSOCIATION}

\section{ANNUAL REPORT FOR 1955}

$I^{\mathrm{T}}$

is sad to record that within a few days after the presentation of the annual report for 1955 of the British Electrical and Allied Industries Research Association* to the annual general meeting of that body on May 2, the Association lost by death its director, Dr. Stanley Whitehead. Dr. Whitehead had served the Association for just over thirty years and he had discharged with distinction the duties of director for the past twelve years.

Since the report was issued, the Association's new laboratories at Leatherhead have been completed and with only a few exceptions the researches which were carried on at Perivale have been transferred to the new quarters and are already established there.

In the introduction to the report it is mentioned, under the heading of "Finance", that a quinquennial period covered by agreement with the Department of Scientific and Industrial Research for the award of grant will shortly come to an end and it is known that, in relation to renewal of grant, the new conditions will make the ratio of grant to grant-earning income less than under the present generous terms. With this in view, and taking account of the improved facilities for research provided by the new laboratories, the "Council is giving serious thought to the ways and means of securing the additional income necessary for the effective and efficient pursuit of the Association's functions".

As in previous years, the report gives brief sum maries of the year's work in each of the research sections, together with a list of reports which have been issued or prepared during that period. There are also included a list of members of the scientific and administrative staff, the composition of the various standing committees, a list of those engaged in the Association's extra-mural researches and

British Electrical and Allied Industries Research Association. Thirty-ffth Annual Report (1st Janusry. 1955, to 31st December, 1955). Pp. 141. (Leatherhead : British Electrical and Allied Indus-
tries Research Association, 1956.) finally a full list of the membership of the Association.

Among the more important of the research items reported may be mentioned the discovery of a new form of intrinsic breakdown arising from mechanical instability in the electrostatic field (see Nature, 176, $1225 ; 1955)$. This discovery occurred in the course of a research into the properties of irradiated dielec. trics, as a result of which it had been shown that irradiation enables polythene, for example, to retain discharge resistance to a much higher temperature. It is also reported that a long-term investigation has been started on the thermal endurance of insulating materials, in which is included the ageing and hydrolysis of 'Terylene'.

In discharge physics a theory of the arc core has been developed which is based on the variation of thermal conduction with temperature. Further new theoretical work has been done on the electron emission from a cathode of low boiling point and on the motion of the cathode spot.

An improvement in the efficiency of utilization of electric cables should result from the publication during the year of a new rating table for paper and varnished cambric cables. These tables, used in association with a group of reports, enable advantage to be taken of higher temperatures allowed for certain types of cable, of variable loading and of a knowledge of the thermal properties of soil. Corresponding work on installation cables has already been incorporated in the thirteenth edition of the Wiring Regulations issued by the Institution of Electrical Engineers. Under "Circuit-Breaking", it is noted that the survey of rates of rise of re-striking voltage, which has already been made for the British $275-\mathrm{kV}$., $132-\mathrm{kV}$., and $66-\mathrm{kV}$. networks, has been extended to the $33 \mathrm{kV}$. system. This investigation and others of a similar character have utilized the Association's network analyser, and it is noteworthy that a number of these problems have required for their solution the special facilities which have been incorporated in this equipment.

In addition to the continuation of work on air blast and oil circuit breakers, it is reported that significant progress has been made on the rupture of heavy currents under low pressures and that an experimental continuously evacuated switch has interrupted the full output of the Perivale test plant.

There is increasing interest, arising largely from the chemical and oil industries, in flame-proofness and intrinsic safety. A new sectional committee has been appointed to direct an expanded programme of work in this field, which is being financed by special contributions from makers, users and the government.

A revised Code of Practice on Earthing is now nearly complete, and a survey has been carried out on the ageing of electrical installations in relation to the incidence of fires.

Research on the properties of high-pressure, hightemperature steam continues, and work has been started on the extension of the Callendar (1939) Steam Tables, the first region under investigation being that up to $5,000 \mathrm{lb}$. $/ \mathrm{in}^{2}$ and $1,400^{\circ} \mathrm{F}$.

A report will soon be published summarizing the results of tests for $10,000 \mathrm{hr}$. on the creep- and corrosion-resistance of steels for high-temperature service in steam plants.

The heading "Unclassified Researches" covers a group of six subjects which are as follows: astro- 